\title{
The haemodynamic significance of asymptomatic ST segment depression assessed by ambulatory pulmonary artery pressure monitoring
}

\author{
RICHARD D LEVY, LEONARD M SHAPIRO, CHRISTINE WRIGHT, \\ LORNA J MOCKUS, KIM M FOX
}

From the National Heart Hospital, London

SUMMARY A transducer-tipped catheter with simultaneous frequency modulated electrocardiograms and a miniaturised tape recorder was used to record ambulatory pulmonary artery pressure for 24-48 hours in 19 men (mean age 57.7) with clinical and angiographic evidence of coronary artery disease. Sixty seven episodes of ST segment depression $(>1 \mathrm{~mm}$ ) were recorded. Thirty five were accompanied by pain of which six occurred at night; in 34 pulmonary artery diastolic pressure rose significantly. In all but two of the 32 episodes of painless ST segment depression (four of which were at night) there was a significant rise in pulmonary artery diastolic pressure. No such rise was found in six normal subjects during exertion. ST segment changes tended to occur before ( 24 episodes) or at the same time (27 episodes) as changes in pulmonary artery diastolic pressure. ST segment depression followed an increase in pulmonary artery diastolic pressure in only 13 episodes. The times to maximum ST depression and maximum pulmonary artery diastolic pressure rise were similar. Painful and painless ST segment depression could not be distinguished on the basis of the configuration of the ST segment or in terms of the changes in the pulmonary artery diastolic pressure.

Ambulatory electrocardiographic monitoring is now widely used in the evaluation of patients with coronary artery disease. ${ }^{12}$ During episodes of angina transient ST segment depression develops. ${ }^{34}$ Similar electrocardiographic changes may also occur in the absence of chest pain. ${ }^{5-7}$ In normal individuals ST segment changes unrelated to myocardial ischaemia may occur during exercise, but in patients with proven coronary artery disease the development of ST segment depression, particularly at low heart rates, is likely to indicate the presence of myocardial ischaemia. ${ }^{8-10}$ Measurements of the left ventricular end diastolic pressure or pulmonary artery pressure by fluid filled catheters in the cornonary care unit or catheter laboratory have shown that left ventricular end diastolic pressure rises during myocardial ischaemia. This was also evident during silent ST segment depression, but the

Requests for reprints to Dr Richard D Levy, National Heart Hospital, Westmoreland Street, London W1M 8BA.

Accepted for publication 19 August 1986 changes were less pronounced than during symptomatic episodes. ${ }^{11-13}$ No such investigations have been performed in ambulant patients, however. We have used ambulatory pulmonary artery pressure monitoring with a transducer tipped catheter to evaluate both painful and painless episodes of ST segment depression ischaemia in patients with coronary artery disease. ${ }^{14}$

\section{Patients and methods}

We studied 19 men (mean (SD) age $57 \cdot 7$ (11) years) with clinical and angiographic evidence of coronary artery disease. Nine had a previous myocardial infarction (8 inferior, 1 anterior). Fifteen had three vessel disease, two had two vessel disease, and one had single vessel disease. All had positive exercise tests and all patients had at least one episode of ST segment depression on ambulatory monitoring over a 24 hour period. In addition, a further six patients with chest pain, normal coronary arteries, and negative exercise tests were studied as controls. 
We excluded patients with evidence of heart failure, other forms of heart disease, and pulmonary vascular disease. All antianginal medication other than glyceryl trinitrate was discontinued at least 48 hours before the study and pulmonary artery pressure monitoring was performed for at least 24 hours, and where possible up to 48 hours. ST segment monitoring was performed throughout this period.

The study was approved by the hospital ethics committee and the patients gave their informed and written consent.

\section{ST SEGMENT MONITORING}

ST segment monitoring was monitored on a frequency modulated recorder and leads CM2 and CM5 were recorded. ${ }^{1}$ The frequency modulated electrocardiogram was replayed on an Oxford MA20 scanner. Changes in the ST segment were measured $80 \mathrm{~ms}$ after the $\mathrm{J}$ point to an accuracy of $0.1 \mathrm{~mm}$ by means of a magnifying lens with graticule. Planar or downsloping ST segment depression of $>1 \mathrm{~mm}$ lasting at least 30 seconds was regarded as important. The heart rate and ST segment changes were analysed on a beat to beat basis for five minutes before each episode and again up to five minutes after the ST segment had returned to basal levels.

PULMONARY ARTERY PRESSURE MONITORING A polyurethane 6 French NIH type catheter with a miniature strain gauge transducer mounted on the tip was used. ${ }^{14}$ This was calibrated after immersion in saline for one hour before use. The catheter was introduced percutaneously via a subclavian vein to the main pulmonary artery under fluoroscopy. The transducer was driven and demodulated by an electrically isolated Gaeltec pre-amplifier. The pulmonary artery pressure was recorded on an Oxford Medilog 1 miniature recorder that had been modified by the insertion of an AM4 pressure module. The pulmonary artery recorder was linked to the frequency modulated electrocardiogram recording by an event button that marked both the frequency modulated electrocardiogram and the pulmonary artery trace.

At the end of 24 to 48 hours of recording the pulmonary artery catheter was removed and the pulmonary artery pressure was replayed via a PB2 unit and a PM3 amplifier. This was displayed on an SE Laboratories 6008 oscillograph. The entire period of recording of the pulmonary artery pressure was displayed on ultraviolet paper and measured with calibrated scale from a zero reference point. The pulmonary artery diastolic pressure was measured during both painful and painless episodes of ST segment depression on a beat to beat basis for five minutes before the onset of the earliest change in pulmonary artery pressure and for five minutes after the pulmonary artery pressure had returned to baseline. In addition, any changes in pulmonary artery pressure not accompanied by ST segment changes were analysed in a similar manner. The pulmonary artery diastolic pressure was measured at the end of expiration to allow for respiratory variation.

\section{ANGINA DIARY}

Patients were instructed to keep diaries during the period of ambulatory pulmonary artery pressure and ST segment monitoring. They were asked to note the time of onset and severity of chest discomfort and their activity at the time of pain. In addition, they were asked to press the event marker so that both the ST segment and pulmonary artery trace were marked.

\section{STATISTICAL ANALYSIS}

A significant change in the basal ST segment, heart rate, or pulmonary artery diastolic pressure was taken to be a change of at least 3 SD from the mean level measured over five minutes before any change in the pulmonary artery pressure. Wilcoxon rank sum testing was used for analysis.

\section{Results}

Sixty seven episodes of ST segment depression $(>1 \mathrm{~mm})$ were recorded in the nineteen patients. Thirty five episodes were accompanied by pain and six of these occurred at night. In all but one of the episodes of ST segment depression accompanied by chest pain there was a significant increase in pulmonary artery diastolic pressure. There were thirty two episodes of ST depression that were not accompanied by chest pain and four of these occurred during the night; in only two was no significant increase in pulmonary artery diastolic pressure found. Most episodes were maximal in lead CM5.

There were 31 episodes in which there was a significant increase in pulmonary artery diastolic pressure without ST segment depression of $\geqslant 1 \mathrm{~mm}$. In 20 of these episodes a minor $(<1 \mathrm{~mm})$ change in the ST segment was recorded, but in 11 episodes no alteration in the ST segment was seen. There was no relation between the severity of ST segment change and the size of the increase in pulmonary artery diastolic pressure (table 1). The relation between the time of onset of ST segment depression and the onset of changes in pulmonary artery diastolic pressure was variable, although ST segment changes tended to occur before or at the same time as changes in palmonary artery diastolic pressure $(p<0.01)$. The onset of ST segment depression preceded the earliest change in pulmonary artery diastolic pres- 
Table 1 Relation between the magnitude of $S T$ segment depression and pulmonary artery diastolic pressure during painful and silent episodes of myocardial ischaemia

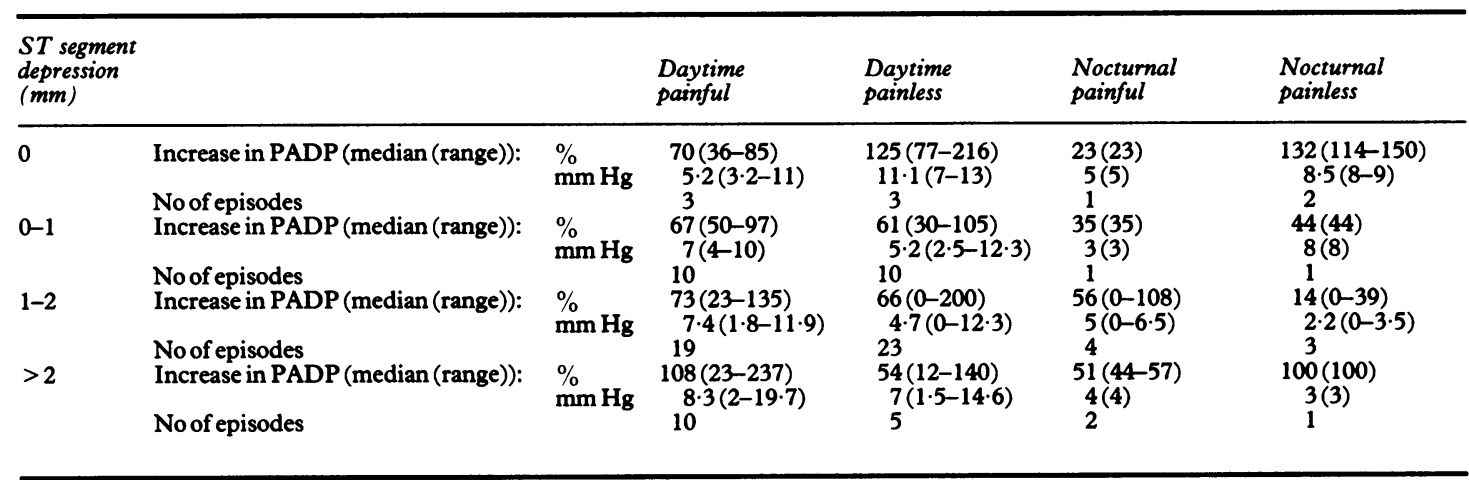

PADP, pulmonary artery diastolic pressure.

Table 2 Pulmonary artery diastolic pressure changes during ST segment depression

\begin{tabular}{|c|c|c|c|c|c|}
\hline & & $\begin{array}{l}\text { Daytime } \\
\text { painful }\end{array}$ & $\begin{array}{l}\text { Daytime } \\
\text { painless }\end{array}$ & $\begin{array}{l}\text { Nocturnal } \\
\text { painful }\end{array}$ & $\begin{array}{l}\text { Nocturnal } \\
\text { painless }\end{array}$ \\
\hline $\begin{array}{l}\text { No of episodes } \\
\text { ST segment depression (median }\end{array}$ & & 29 & 28 & 6 & 4 \\
\hline $\begin{array}{l}\text { (range)(mm)) } \\
\text { Increase in PADP (median (range)): }\end{array}$ & $\begin{array}{l}\% \\
\mathrm{~mm} \mathrm{Hg}\end{array}$ & $\begin{array}{c}1.5(1-4) \\
87.5(20-237) \\
7.5(1.8-19.7)\end{array}$ & $\begin{array}{c}1 \cdot 4(1-3 \cdot 2) \\
66(0-200) \\
4 \cdot 9(0-14 \cdot 6)\end{array}$ & $\begin{array}{c}1 \cdot 5(1-2 \cdot 8) \\
53(0-108) \\
4.5(0-6 \cdot 5)\end{array}$ & $\begin{array}{c}1 \cdot 4(1-2 \cdot 3) \\
26(0-200) \\
2 \cdot 6(0-3 \cdot 5)\end{array}$ \\
\hline $\begin{array}{l}\text { PADP before each episode } \\
\text { (median (range) }(\mathrm{mm} \mathrm{Hg}))\end{array}$ & & $8 \cdot 2(4-18)$ & $8 \cdot 3(2-15 \cdot 3)$ & $9 \cdot 5(7-18)$ & $7(3-18)$ \\
\hline
\end{tabular}

PADP, pulmonary artery diastolic pressure.

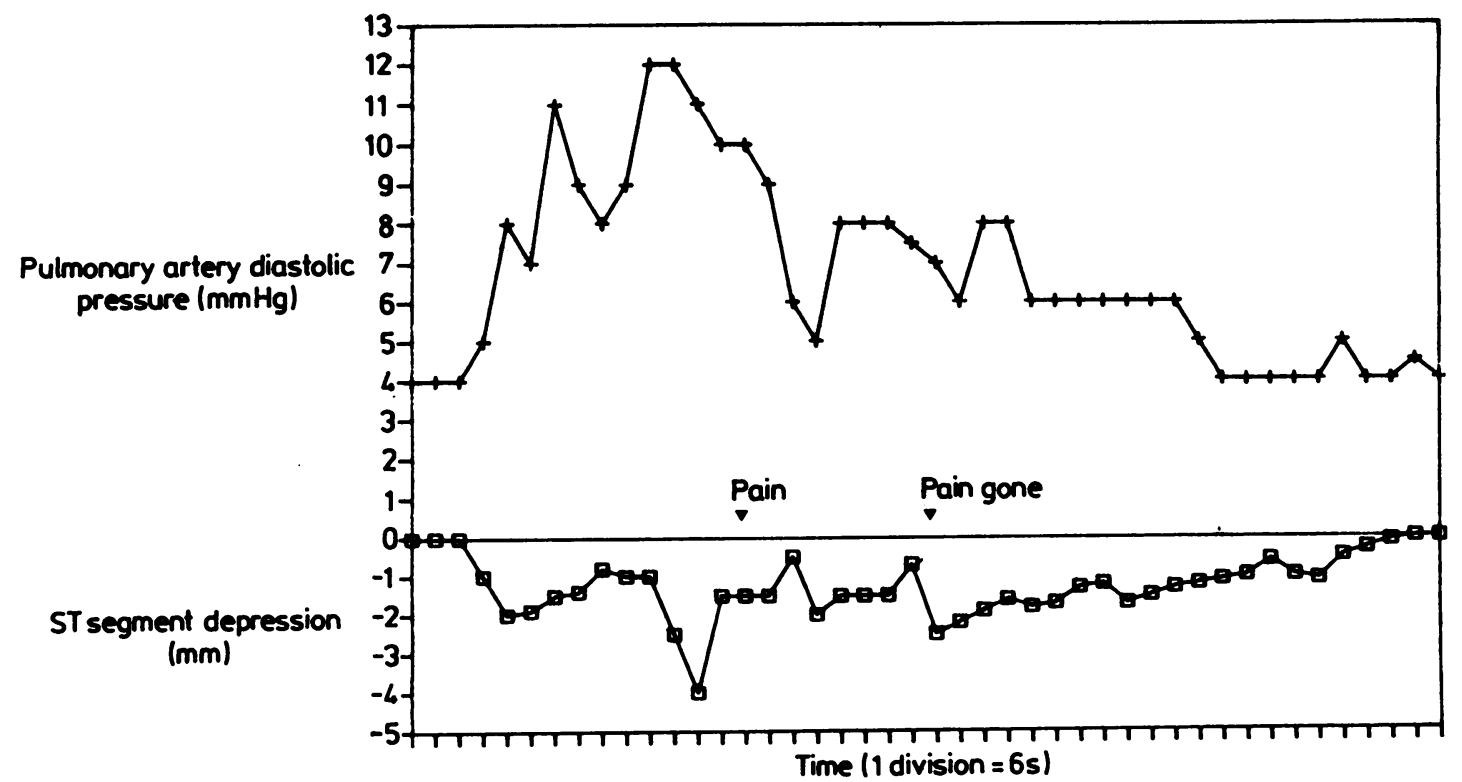

Figure Changes in pulmonary artery diastolic pressure and the ST segment during an episode of myocardial ischaemia. 
sure in 24 episodes. In a further 27 episodes the pulmonary artery diastolic pressure and ST segment changes occurred simultaneously. ST segment depression followed an increase in pulmonary artery diastolic pressure in only 13 episodes.

There were no acute changes in pulmonary artery diastolic pressure during ambulatory monitoring in the six control subjects. When they were exercised the median increase in pulmonary artery diastolic pressure was $0 \mathrm{~mm} \mathrm{Hg}$ (range 0-3). This increase in pulmonary artery systolic pressure was similar to that recorded in patients with coronary artery disease.

\section{PAINFUL VERSUS PAINLESS EPISODES}

The magnitude of ST segment depression was similar in episodes that occurred with or without chest pain and in episodes that occurred during the day or at night $(p<0.05)$ (table 1). Increases in pulmonary artery diastolic pressure were also similar during episodes of painful and painless nocturnal and daytime ST segment depression. The basal pulmonary artery diastolic pressure in the five minutes before the onset of ST segment changes was no different in painful and painless episodes of ST segment depression whether or not they occurred during the day or at night (table 2). The maximum pulmonary artery diastolic pressure tended to coincide with the point of maximum ST segment depression and both of these preceded the complaints of chest pain (fig).

\section{Discussion}

There is considerable interest in the significance of silent myocardial ischaemia. ${ }^{41215}$ While prognostic information and the therapeutic implications of painless ST segment changes is still under investigation, ${ }^{16}{ }^{17}$ previous studies of left ventricular function measured in the coronary care unit have shown that left ventricular end diastolic pressure rises during painless myocardial ischaemia. ${ }^{11}$ In this study of ambulant patients we have shown that transient abnormalities of left ventricular functions, as reflected by alterations in pulmonary artery diastolic pressure, do occur during painful and painless episodes of ST segment depression. In 1958 Müller and Rørvik first saw an abnormal increase in pulmonary artery pressure in two patients with spontaneous angina. ${ }^{18}$ Other studies have confirmed these observations. ${ }^{19-21}$ In the absence of pulmonary vascular disease and mitral valve obstruction, the pulmonary artery diastolic pressure correlates well with left ventricular pressure. ${ }^{1422}$ We have used this relation to develop a technique to record the pulmonary artery pressure in ambulant patients. ${ }^{14}$ This has permitted the significance of symptomatic and asymptomatic ST segment changes to be examined in ambulant patients. The introduction of a cardiac catheter into the left ventricle or pulmonary artery with recordings made in the coronary care unit or catheter laboratory does not permit normal physiology to be studied and considerable caution is necessary in interpreting the findings of such studies in painless ischaemia.

Several studies have shown that only about $30 \%$ of episodes of ST segment depression that occur in patients with angina pectoris during 24 hour ambulatory monitoring are accompanied by chest pain. ${ }^{122324}$ Examination by positron tomography has confirmed that painless episodes of ST segment depression are accompanied by myocardial ischaemia detected by abnormal uptake of rubidium-82. ${ }^{25-27}$ We found that each episode of ST segment depression was accompanied by an increase in pulmonary artery diastolic pressure. The extent of this increase varied from episode to episode even within the same patient, but in general both painful and painless episodes of ST segment depression were accompanied by similar increases in pulmonary artery diastolic pressure. Furthermore, the increase in pulmonary artery diastolic pressure was independent of the magnitude of ST segment depression recorded on ambulatory monitoring. Indeed, when only a minor change in the ST segment was seen it was still possible for there to be a large increase in pulmonary artery diastolic pressure. It is impossible to assess the full extent of ST segment changes in only two electrocardiographic channels. There was no alteration in pulmonary artery diastolic pressure in the control subjects during ambulatory monitoring or treadmill exercise.

We cannot be certain that the patient pressed the event button at the same time as the onset of chest pain. The timing of the onset of ST segment change, rise in pulmonary artery diastolic pressure, and the patient's awareness of the development of chest pain must be interpreted with caution. ${ }^{28} 29$ The sequence of events was similar, however, to that described in previous. catheterisation studies 6121330 in which the ST segment changes usually preceded changes in pulmonary artery diastolic pressure and both occurred before the patient complained of chest pain.

Our finding that symptomatic and silent episodes of ST segment depression are associated with considerable alterations in left ventricular function is similar to previous reports. ${ }^{11}$ Because patients took glyceryl trinitrate we were unable to compare the duration of rise in pulmonary artery diastolic pressure during silent and symptomatic episodes of ST segment depression. 
In conclusion, episodes of painful and painless ST segment depression are associated with similar haemodynamic changes. The prognostic and therapeutic implications of these findings need to be explored.

We thank the Clinical Research Committee of the National Heart and Chest Hospitals for financial support.

\section{References}

1 Quyyumi AA, Mockus L, Wright C, Fox KM. Morphology of ambulatory ST segment changes in patients with varying severity of coronary artery disease. Investigation of the frequency of nocturnal ischaemia and coronary spasm. $\mathrm{Br}$ Heart $\mathfrak{f}$ 1985;53:186-93.

2 Kunkes SH, Pichard A, Meller J, Garlin R, Herman MV, Kupersmith J. Use of the ambulatory electrocardiogram to diagnose coronary artery disease. $\mathcal{F}$ Electrocardiol 1980;13:341-6.

3 Bala Subramanian V, Lahiri A, Green HL, Stott FD, Raftery EB. Ambulatory ST segment monitoring: problems, pitfalls, solutions, and clinical applications. Br Heart $\mathcal{F}$ 1980;44:419-25.

4 Maseri A, Pesola A, Mimmo R, Chierchia S, L'Abbate. Pathogenetic mechanism of angina at rest [Abstract]. Circulation 1975;52(suppl 2):89.

5 Stern S, Tzivoni D. Early detection of silent ischaemic heart disease by 24-hour electrocardiographic monitoring of active subjects. Br Heart $\mathcal{F}$ 1974;36:481-6.

6 Selwyn AP, Fox K, Eves M, Oakley D, Dargie H, Shillingford J. Myocardial ischaemia in patients with frequent angina pectoris. $\mathrm{Br} \mathrm{Med} \mathcal{F}$ 1978;ii:1594-6.

7 Schang SL, Pepine C. Transient asymptomatic ST segment depression during daily activity. Am $₹ \mathrm{Car}-$ diol 1977;39:396-402.

8 Armstrong WF, Jordan JW, Morris S, McHenry PL. Prevalence and magnitude of ST segment and $T$ wave abnormalities in normal men during continuous ambulatory electrocardiography. $\mathrm{Am} \mathfrak{f}$ Cardiol 1982;49:1638-42.

9 Gettes LS. Painless myocardial ischemia. Chest 1974; 66:612-3.

10 Cohn PF. Prognosis and treatment of asymptomatic coronary artery disease. $\mathcal{F} \mathrm{Am}$ Coll Cardiol 1983; 1:959-64.

11 Chierchia S, Lazzari M, Freedman SB, Brunelli C, Maseri A. Impairment of myocardial perfusion and function during painless myocardial ischemia. $\mathcal{f} \mathrm{Am}$ Coll Cardiol 1983;1:924-30.

12 Guazzi M, Polese A, Fiorentini C, Magrini F, Olivari MT, Bartorelli C. Left and right heart haemodynamics during spontaneous angina pectoris. Comparison between angina with ST segment depression and angina with ST segment elevation. Br Heart $\mathcal{F}$ 1975;37:401-13.

13 Figueras J, Singh B, Ganz W, Charuzi Y, Swan H. Mechanism of rest and nocturnal angina: observations during continuous hemodynamic and electrocardiographic monitoring. Circulation 1979;
59:955-68.

14 Levy RD, Cunningham D, Shapiro LM, Wright C, Mockus L, Fox KM. Continuous ambulatory pulmonary artery pressure monitoring: a new method using a transducer tipped catheter and a simple recording system. Br Heart $\mathcal{F}$ 1986;55:336-43.

15 Chierchia S, Brunelli C, Simonetti I, Lazzari $M$, Maseri A. Sequence of events in angina at rest: primary reduction in coronary flow. Circulation 1980; 61:759-68.

16 Pepine CJ. Clinical aspects of silent myocardial ischemia in patients with angina and other forms of coronary artery disease. Am $\mathcal{f} \mathrm{Med}$ 1986;80(suppl 4C):25-34.

17 Gottleib SO, Weisfeld ML, Ouyang P, Mellits ED, Gerstenblith G. Silent ischemia as a marker for early unfavourable outcomes in patients with unstable angina. N Engl f Med 1986;314:1214-8.

18 Müller O, Rørvik K. Haemodynamic consequences of coronary artery disease with observations during anginal pain and on the effect of nitroglycerine. Br Heart $\mathcal{F}$ 1958;20:302-10.

19 Lecerof $\mathrm{H}$. Central haemodynamics during spontaneous angina pectoris. $\mathrm{Br}$ Heart $\mathcal{f}$ 1974;36:1087-91.

20 Friesinger GC, Conti CHR, Pitt B. Observations on left ventricular pressure during angina pectoris [Abstract]. Circulation 1967;36(suppl 2):115.

21 Roughgarden JW. Circulatory changes associated with spontaneous angina pectoris. Am $\mathcal{F}$ Med 1966;41: 947-61.

22 Rackley CE, Russell RO Jr, Moraski RE, Mantle JA. Recent advances in hemodynamic studies in patients with acute myocardial infarction. In: $\mathrm{Yu} P N$, Goodwin JF, eds. Progress in cardiology. Vol 5. Philadelphia: Lea and Febiger, 1976:201-26.

23 Allen RD, Gettes LS, Phalen C. Painless ST depression in patients with angina pectoris. Chest 1976; 69:467-73.

24 Quyyumi AA, Wright C, Fox K. Ambulatory electrocardiographic ST segment changes in healthy volunteers. Br Heart $\mathcal{F}$ 1983;50:460-4.

25 Deanfield JE, Shea M, Ribiero P, et al. Transient ST segment depression as a marker of myocardial ischemia during daily life. Am $\mathcal{f}$ Cardiol 1984; 54:1195-200.

26 Deanfield JE, Selwyn AP. Character and causes of transient myocardial ischemia during daily life: implications for treatment of patients with coronary disease. Am $\mathcal{F}$ Med 1986;80(suppl 4C):18-24.

27 Deanfield JE, Shea ML, Wilson RA, et al. Direct effects of smoking on the heart: silent ischemic disturbances of coronary flow. Am $\mathcal{F}$ Cardiol 1986; 57:1005-10.

28 Cecci AC, Dovellini EV, Marchi F, Pucci P, Santoro GM, Fazzini PF. Silent myocardial ischemia during ambulatory electrocardiographic monitoring in patients with effort angina. $\mathcal{F} \mathrm{Am}$ Coll Cardiol 1983;1:934-9.

29 Droste C, Roskamm H. Experimental pain measurement in patients with asymptomatic myocardial ischemia. $\mathcal{f}$ Am Coll Cardiol 1983;1:940-5.

30 Scheidt S. Wolk M, Killip T. Unstable angina pectoris-natural history, hemodynamics, uncertainties of treatment and the ethics of clinical study. Am $\mathcal{F}$ Med 1976;60:409-17. 